\title{
Microsurgical Repair of Severed Thoracic Spinal Cord and Clinical Outcome: Technical Case Report
}

Chandrasekaran Kaliaperumal ( $\square$ ckaliaperumal@gmail.com )

The Royal Infirmary of Edinburgh, Little France

\section{Case report}

Keywords: Spinal injury, Stab injury, Penetrating injury to Spinal cord, Spinal cord Repair ASIA score, Brown-Séquard syndrome

Posted Date: September 23rd, 2021

DOl: https://doi.org/10.21203/rs.3.rs-915286/v1

License: (9) This work is licensed under a Creative Commons Attribution 4.0 International License. Read Full License 


\section{Abstract}

This report describes a case of successful repair of severed thoracic spine in a young man who presented with a penetrating stab injury to spine resulting in Brown-Séquard syndrome. Surgical technique and postoperative management is discussed.

A 34-year-old fit and well healthy man was admitted with a history of stab injury to the thoracic spine at thoracic T2/3 level with ASIA impairment score (AIS) score D with an incomplete spinal cord affecting his left lower limb with complete paralysis and right lower limb paresis with impaired sensation below T6 level to L5. Neuroimaging confirmed a penetrating knife injury traversing the T2/3 level causing hemisection of the spinal cord confirmed intraoperatively. He underwent an urgent exploratory surgery of his spine and a T2/3 laminectomy was performed to aid removal of the knife. The dura was noted to be contused and severed spinal cord was noted to be severed with associated cord oedema. A microsurgical repair of the severed cord was performed with duroplasty followed by intense neuro-rehabilitation. On a three month follow up his AIS score is $E$ with lower limb power is $5 / 5$ bilaterally and he is able to mobilise independently up to 8-10 steps without any supportive aid and with crutches he is independently functional and mobile.

This is the first documented case of microsurgical repair of severed thoracic spinal cord secondary to traumatic knife injury. In the management of such scenario, apart from the removal of foreign body, repair of the cord with duroplasty should be carefully considered. The role of spinal neuroplasticity in healing following timely repair of the spinal cord along with intense rehabilitation remains the key. This had resulted in a good clinical and functional outcome with in a 12 month period.

\section{Introduction}

Spinal cord injury (SCl) is a severe neural trauma and depending on the damaged segment and severity of the trauma, it is classified into complete and incomplete $\mathrm{SCl}$. SCl is also a debilitating neurological condition with tremendous socioeconomic impact on the affected individuals and the health care system. Etiologically, more than $90 \%$ of $\mathrm{SCl}$ cases are traumatic and caused by incidences such as traffic accidents, violence, sports or falls[6,13,16]. Adults older than 60 years of age whom suffer $\mathrm{SCl}$ have considerably worse outcomes than younger patients, and their injuries usually result from falls and agerelated bony changes[3,16]. In this report, a young and healthy male presenting with a penetrating stab injury to his thoracic spine and the management outcome is described with an emphasis on the surgical technique.

\section{Case Presentation}

A fit and well 34-year-old man was admitted to the emergency service with multiple stab injuries to posterior thorax and occiput with a retained knife in his interscapular area. He remained haemodynamically stable and neurological examination revealed normal power in upper limbs and a 4/5 
power in his right lower limb, $0 / 5$ power in his left lower limb. Sensory examination revealed an intact pin prick and light touch from $\mathrm{C} 2-\mathrm{T} 4$, altered sensation $\mathrm{T} 5$, absent sensation to pin prick and light touch from T6-S2 with intact perianal sensation. He had a Motor incomplete- ASIA impairment score (AIS) D score. A CT spine was confirmed trajectory of the knife traversing the superior T2 right lamina into left inferior posterior T2 vertebral body. There was no associated vascular injury associated ( Fig.1,2) .

\section{Surgical Technique:}

A thoracic T2 and T3 laminectomy and removal of foreign body was performed within 3 hours of presentation. The knife was noted to be retained in the right paraspinal region with a trajectory of the knife tip to the midline(Fig.3,4). A $10 \mathrm{cms}$ midline incision made and connecting the oblique right paraspinal wound. The paraspinal muscles dissected and laminae of T2/3 expose and T2/3 laminectomy completed with high speed drill.

Intra operative findings: Under microscopic guidance, the knife was removed following the laminectomy with minimal manipulatory movement. Care was taken not to move the knife perpendicular to the cord to avoid further damage. The tip of the knife penetrated the right side of the cord causing hemisection of the cord landing in the vertebral body. The dura appeared contused and severed (Fig.5). 8 mgs dexamethasone was administered intravenously after the knife was removed from the cord. The torn right hemi cord was sutured with continuous 7'0 prolene (Fig.6,7). The pia arachnoidal layer was included in the suturing procedure in a circumferential manner to oppose the torn cord. Haemostasis secured with Floseal ${ }^{\circledR}$. Dural margins were trimmed and a watertight duroplasty was performed Duraguard ${ }^{\mathrm{TM}}$ with $3^{\prime} 0$ prolene. Tisseel fibrin glue was used to seal the duroplasty margins. Wound closed in layers. No postoperative surgical complications were encountered.

\section{Post-operative course:}

He was treated in the intensive care unit and was noted to have complete loss of power in both legs for 8 days and a power of $1 / 5$ noted in his left extensor hallucis longus that improved to $4 / 5$ over 6 weeks. Sensory examination revealed a Brown-Séquard syndrome pattern with loss of pinprick sensation and temperature below T4 on the right side which recovered on the left side. Post-operative spinal MRI at day 4 revealed high signal at the repair sight at the T2/3 level (Fig.8,9). An MRI performed at 3 months ( Fig $10,11)$ revealed sign of significant spinal cord injury in the and micro-hemorrhages in the cord above and below the level of injury with associated post-operative changes. His ASIA score improved to E from D.

At a 12 month follow-up his is mobilising independently with normal lower limb power and needs crutches for maintaining truncal balance.

\section{Discussion}

Stab wounds of the spinal cord represent approximately $26 \%$ of all spinal cord injuries $[6,10]$ and remains the most common cause of traumatic Brown-Séquard syndrome[3,7,9,11,12,13,15]. In this case, the 
patient had a picture of post traumatic Brown-Séquard syndrome like picture with complete recovery of the motor functions in a 3 month period with persistent sensory on the right side. Middleton et al describe in their study that approximately $42 \%$ of patients with traumatic SCl have complete dysfunction without any movement or sensation below the site of injury and this may not be applicable to penetrating trauma to spinal cord, nevertheless it gives us an account of the severity of the pathology and clinical implications [8]. They have also eluded to the fact that only $14.3 \%$ of all SCls are believed to be anatomically complete injuries, while the remainder of SCls are considered as an incomplete functional deficiency with a few spared connections that could be established under proper interventions [8]. In this case, the knife injury had resulted in a hemi section of the cord contributing to incomplete functional status. It is useful to note that the therapeutic options for traumatic $\mathrm{SCl}$ includes surgical decompression, anti-inflammatory drugs, hyperbaric oxygen therapy, and rehabilitation interventions[14]. SCl is still associated with a high disability rate despite the intensive rehabilitation programs carried out in hospitals worldwide $[1,14,16]$.

In the case described one may argue if microsurgical repair is superior to just removal of the knife without repair of the cord or instillation of fibrin glue to the severed margins. There is no evidence to prove the efficacy of a specific technique leading to good functional recovery. Administration of Dexamethasone in this case is following the observation of the severed cord and the rationale can be questioned. Dural reconstruction following cord repair is vital in preventing post-operative complications compromising recovery.

The clinical outcomes of $\mathrm{SCl}$ depend on the severity and location of the lesion and may include partial or complete loss of sensory and/or motor function below the level of injury. Literature describe that cervical level of the spinal cord (50\%) with the single most common level affected being $\mathrm{C} 5$ and the thoracic level (35\%) and lumbar region (11\%) in case of Traumatic SCI [6,8]. In case of penetrating cord injury the etiology is varied and there is report of penetrating missile injury and management by Kumar et al [17] where the emphasis on conservative management to surgical removal of the foreign body to avoid iatrogenic deficits. There are reports of accidental penetrating injury to cord secondary to Nail gun injury and wooden fragment penetration causing cauda equina syndrome where role of surgery is described [18-20].

With recent advancements in medical procedures and patient care, SCI patients often survive these traumatic injuries and live for decades after the initial injury [16]. Studies have shown that 40-year survival rate of these individuals was $47 \%$ and $62 \%$ for persons with tetraplegia and paraplegia, respectively $[9,16]$.The life expectancy of $\mathrm{SCl}$ patients highly depends on the level of injury and preserved functions. Mary Joan Roach et al in their recent study have concluded that the patients with penetrating $\mathrm{SCl}$ showed more complete injuries and lower surgery rates with worse functional outcome at one year [21]. In our case, these evidence gives us an understanding of long term implications in the management of SCl. Kevin Morrow et al have concluded in their analysis pertaining to penetrating SCl that younger patients are affected and they utilize more health care resources. Surgery is undertaken to limiting progression of neurological deficits, stabilization and to control infection [22]. 
In this case, the patient had signs and symptoms of Incomplete cord injury/ Brown-Sequard syndrome that was successfully managed with timely surgical intervention, intense post-operative care and physiotherapy. There is evidence to support that Neuroplasticity plays an important in SCl recovery and physiologically based approach for the rehabilitation of walking has developed, translating evidence for activity-dependent neuroplasticity and the neurobiological control of walking $[4,5]$. Neuroplasticity occurs at multiple levels following SCl: Cortical, subcortical, brainstem and spinal cord both short-term and longterm, supporting the need for long term rehabilitation in these cases [5].

There is a paucity of reports eluding to repair of the spinal cord secondary to stab injury and particularly to the thoracic spine. Spinal cord repair is technically feasible however several factors should be considered, particularly the nature of injury, type of the foreign body, age of patient, time to repair from trauma and neurological status of the patient along clear understanding of treatment options. This case demonstrates that with multidisciplinary input, a combination of prompt surgical intervention and rehabilitation has helped an adult patient with penetrating stab injury to the spinal cord.

\section{Conclusion}

This is the first documented case of hemi-section of the thoracic cord secondary to penetrating knife injury that was successfully repaired and the patient has made a successful functional recovery. The aim of the treatment is to safely remove the foreign body followed by a meticulous and prompt microsurgical repair with water tight duroplasty. The clinical outcome depends on multiple factors including the nature of injury, appropriate preoperative imaging to determine the type of spinal cord injury, clinical judgement and expertise with a suitable post-operative multi-disciplinary treatment facility providing an intensive care and rehabilitation support. The role of spinal neuroplasticity following repair plays a significant role in spinal cord healing and this is supported by provision of high quality intensive medical care. This concurs with recent evidence that in penetrating $\mathrm{SCl}$, surgery is undertaken to limit progression of neurological deficits, stabilization or infection control. Long term follow-up along with psychological support is recommended.

\section{Declarations}

Ethics approval: Not applicable

Consent to participate: Written consent is obtained from the patient for purpose of publication.

Availability of Data and materials: Data sharing not applicable to this article as no datasets were generated or analysed during the current study

Competing Interests: None

Funding: No funding was received for the preparation of this article 
Authors contribution: The author is the primary Consultant who treated this patient and was responsible for the write up of this technical case report.

Acknowledgements: We are very grateful to the neuro-intensive care physicians, Nursing staff in the Intensive care unit in the Royal Infirmary of Edinburgh, UK and the Rehabilitation team in the Queen Elizabeth Spinal injuries unit, Glasgow, UK.

\section{Author's information:}

Mr Chandrasekaran Kaliaperumal FRCSI FRCSEd( Neuro.Surg), Consultant Neurosurgeon, Department of Neurosurgery, Royal Infirmary of Edinburgh, Edinburgh, EH16 4SA and Honorary Senior Clinical Lecturer in the University of Edinburgh, UK

\section{References}

1. Arsalan Alizadeh, Scott Matthew Dyck, Soheila Karimi-Abdolrezaee. Traumatic Spinal Cord Injury: An Overview of Pathophysiology, Models and Acute Injury Mechanisms. Front Neurol. 2019, 10: 282. Published online 2019 Mar 22. doi: 10.3389/fneur.2019.00282.

2. Hachem LD, Ahuja CS, Fehlings MG. Assessment and management of acute spinal cord injury: from point of injury to rehabilitation. J Spinal Cord Med. (2017) 40:665-75.

10.1080/10790268.2017.1329076.

3. WHO WHO I Spinal Cord Injury. WHO, Fact sheet N 384 (2013). Available online at: https://www.who.int/news-room/fact-sheets/detail/spinal-cord-injury.

4. Oyinbo CA. Secondary injury mechanisms in traumatic spinal cord injury: a nugget of this multiply cascade. Acta Neurobiol Exp. 2011,71:281-299.

5. Amendola L, Corghi A, Cappuccio M, De lure F. Two cases of Brown-S qard syndrome in penetrating spinal cord injuries. Eur Rev Med Pharmacol Sci 2014,18(1):2-7.

6. Park SD, Kim SW, Jeon I. Brown-Sequard Syndrome after an Accidental Stab Injury of Cervical Spine: A Case Report. Korean J Neurotrauma. 2015 Oct,11(2):180-2. doi: 10.13004/kjnt.2015.11.2.180. Epub 2015 Oct 31. PMID: 27169090, PMCID: PMC4847515.

7. Johnson S, Jones M, Zumsteg J.J . Brown-S quard syndrome without vascular injury associated with Horner's syndrome after a stab injury to the neck.

8. Middleton JW, Dayton A, Walsh J, Rutkowski SB, Leong G, Duong S, et al. . Life expectancy after spinal cord injury: a 50-year study. Spinal Cord. (2012) 50:803-11. 10.1038/sc.2012.55.

9. Shavelle RM, Paculdo DR, Tran LM, Strauss DJ, Brooks JC, DeVivo MJ. Mobility, continence, and life expectancy in persons with Asia Impairment Scale Grade D spinal cord injuries. Am J Phys Med Rehabil. (2015) 94:180-91.10.1097/PHM.0000000000000140. Spinal Cord Med. 2016,39(1):111-4. doi: 10.1179/2045772314Y.0000000297. Epub 2015 Feb 9.

10. Peacock WJ, Shrosbree RD, Key AG. A review of 450 stab wounds of the spinal cord. S Afr Med J1977,51(26):961-4. 
11. Pouw MH, van de Meent $H$, van Middendorp JJ, Hirshfeld S, Thietje R, van Kampen A, et al. Relevance of the diagnosis traumatic cervical Brown-S quard-Plus syndrome: an analysis based on the neurological and functional recovery in a prospective cohort of 148 patients. Spinal Cord 2010,48(8):614-8.

12. Kakulas BA. Neuropathology: the foundation for new treatments in spinal cord injury. Spinal Cord. 2004,42:549-563.

13. Ahuja CS, Nori S, Tetreault L, Wilson J, Kwon B, Harrop 172 J, Choi D, Fehlings MG. Traumatic spinal cord injury-repair and regeneration. Neurosurgery. 2017,80:S9-S22.

14. Ya Zheng, 1 Ye-Ran Mao, 1 Ti-Fei Yuan, PhD,2,3,* Dong-Sheng Xu, MD,1,4, ${ }^{\star}$ and Li-Ming Cheng, MD, PhD4,5,* Multimodal treatment for spinal cord injury: a sword of neuroregeneration upon neuromodulation. Neural Regen Res. 2020 Aug, 15(8): 1437-1450. Published online 2020 Jan 28. doi: 10.4103/1673-5374.274332

15. Ramadan WS, Abdel-Hamid GA, Al-Karim S, Zakar N, Elassouli MZ. Neuroectodermal stem cells: A remyelinating potential in acute compressed spinal cord injury in rat model. J Biosci. 2018,43:897909.

16. Wilson JR, Cadotte DW, Fehlings MG. Clinical predictors of neurological outcome, functional status, and survival after traumatic spinal cord injury: a systematic review. J Neurosurg Spine. (2012) 17(1Suppl.):11-26. 10.3171/2012.4.AOSPINE1245

17. Kumar, A., Pandey, P. N., Ghani, A., \& Jaiswal, G. (2011). Penetrating spinal injuries and their management. Journal of craniovertebral junction \& spine, 2(2), 57-61. https://doi.org/10.4103/0974-8237.100052

18. Goyal RS, Goyal NK, Salunke P. Non- missile penetrating Injuries. Indian Journal of Neurotrauma (IJNT) 2009,6:81-4.

19. Pal D, Timothy J, Marks P. Penetrating spinal injury with wooden fragments causing cauda equina syndrome: Case report and literature review. Eur Spine J. 2006,15:S574-7.

20. Lunawat SK, Taneja DK. A foreign body in the spinal canal: A case report. J Bone Joint Surg Br. 2000,82:267-8.

21. Roach, M. J., Chen, Y., \& Kelly, M. L. (2018). Comparing Blunt and Penetrating Trauma in Spinal Cord Injury: Analysis of Long-Term Functional and Neurological Outcomes. Topics in spinal cord injury rehabilitation, 24(2), 121-132. https://doi.org/10.1310/sci2402-121

22. Morrow, K. D., Podet, A. G., Spinelli, C. P., Lasseigne, L. M., Crutcher, C. L., II, Wilson, J. D., Tender, G. C., \& DiGiorgio, A. M. (2019). A case series of penetrating spinal trauma: comparisons to blunt trauma, surgical indications, and outcomes, Neurosurgical Focus FOC, 46(3), E4. Retrieved Aug 14, 2021, from https://thejns.org/focus/view/journals/neurosurg-focus/46/3/article-pE4.xml

\section{Figures}




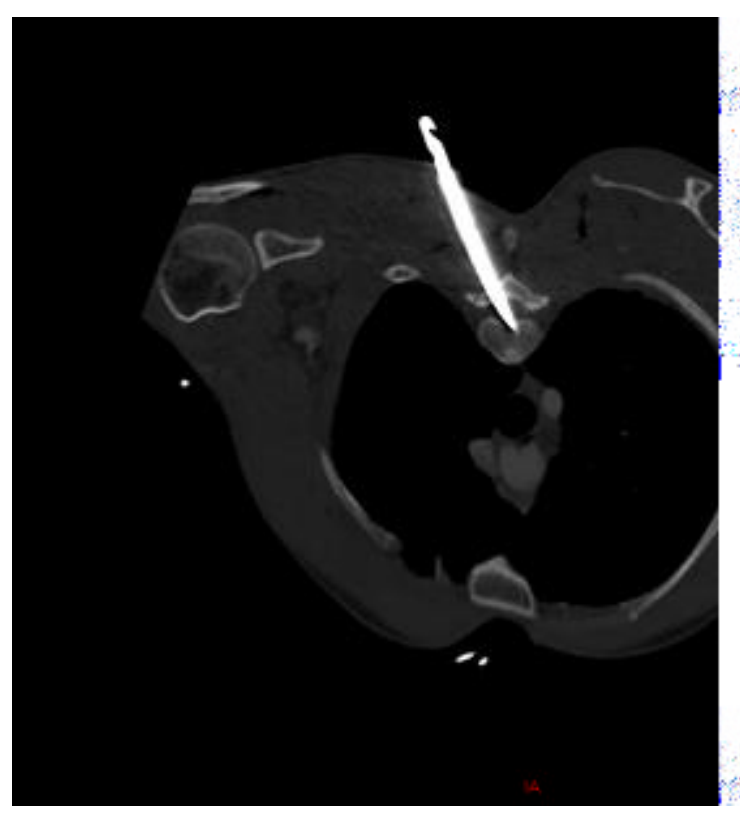

\section{Figure 1}

Axial CT scan of the thorax demonstrating foreign body (knife) in the spinal canal in an oblique position reaching the anterior aspect of the spinal canal.

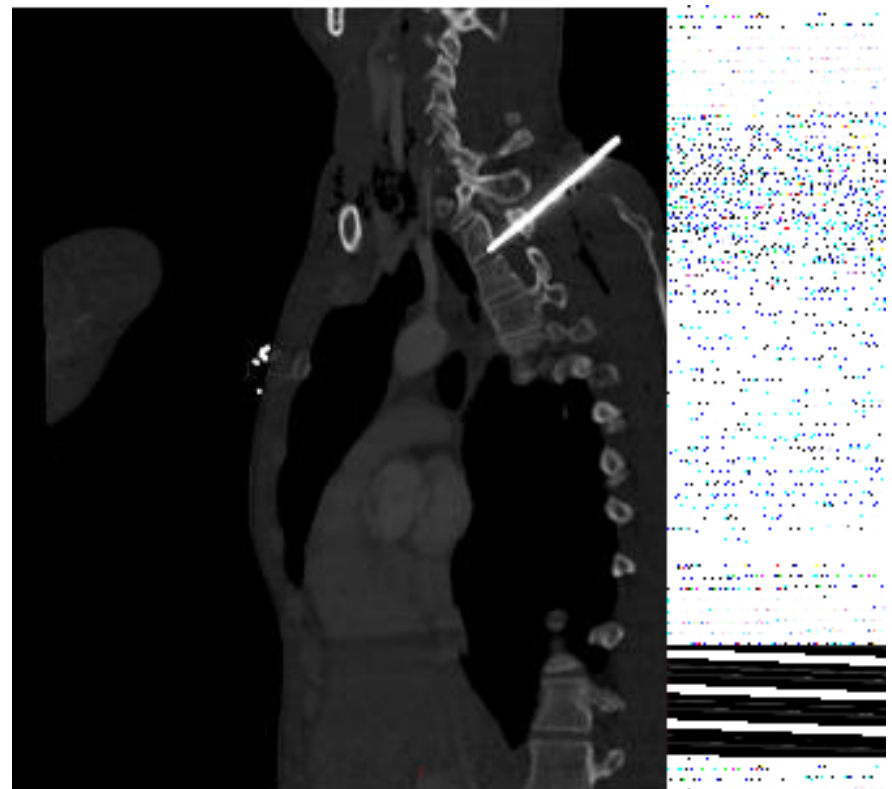

\section{Figure 2}

Sagittal CT of thorax demonstrating position of the knife corresponding the T2 and T3 spinal level. 


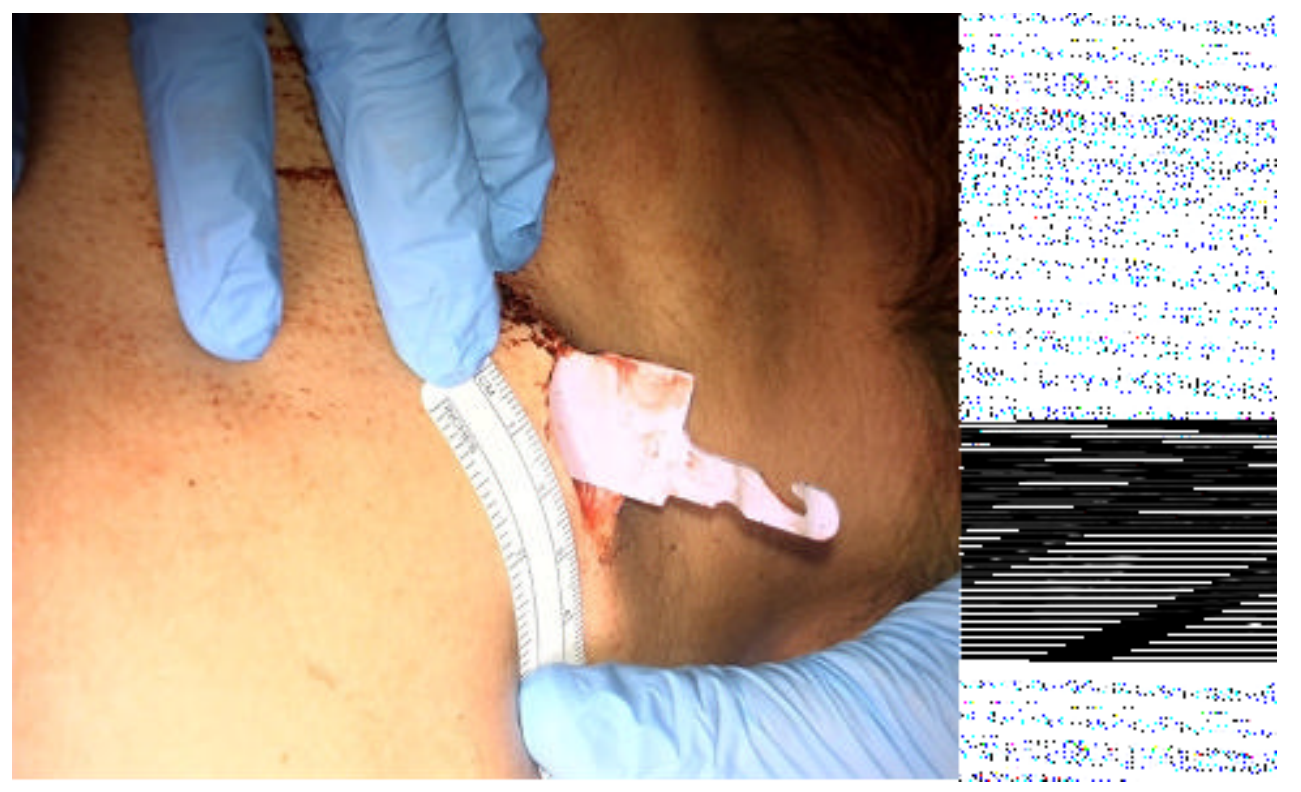

Figure 3

Pre-operative picture of the knife in the interscapular region.

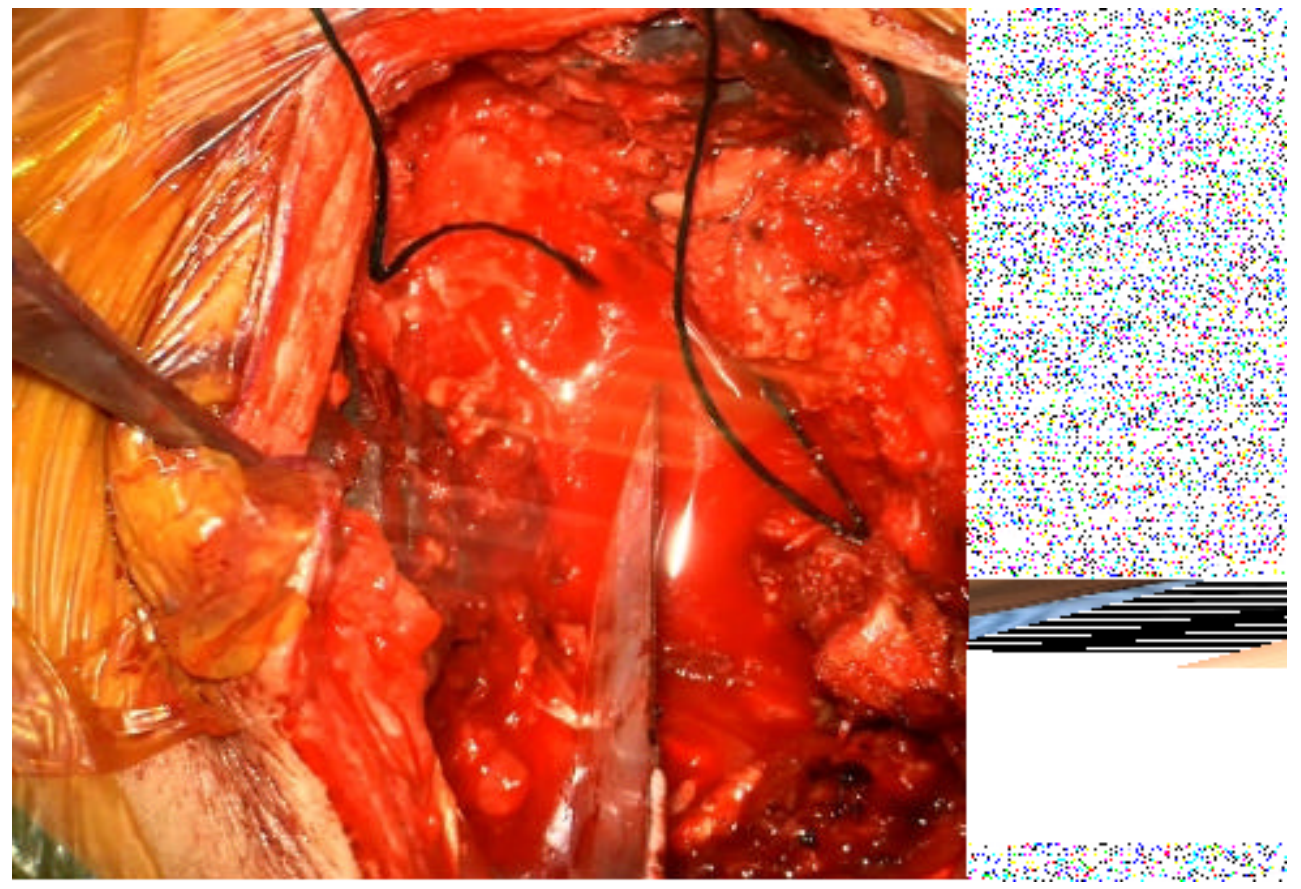

Figure 4

Intra-operative picture after muscle dissection before the laminectomy 


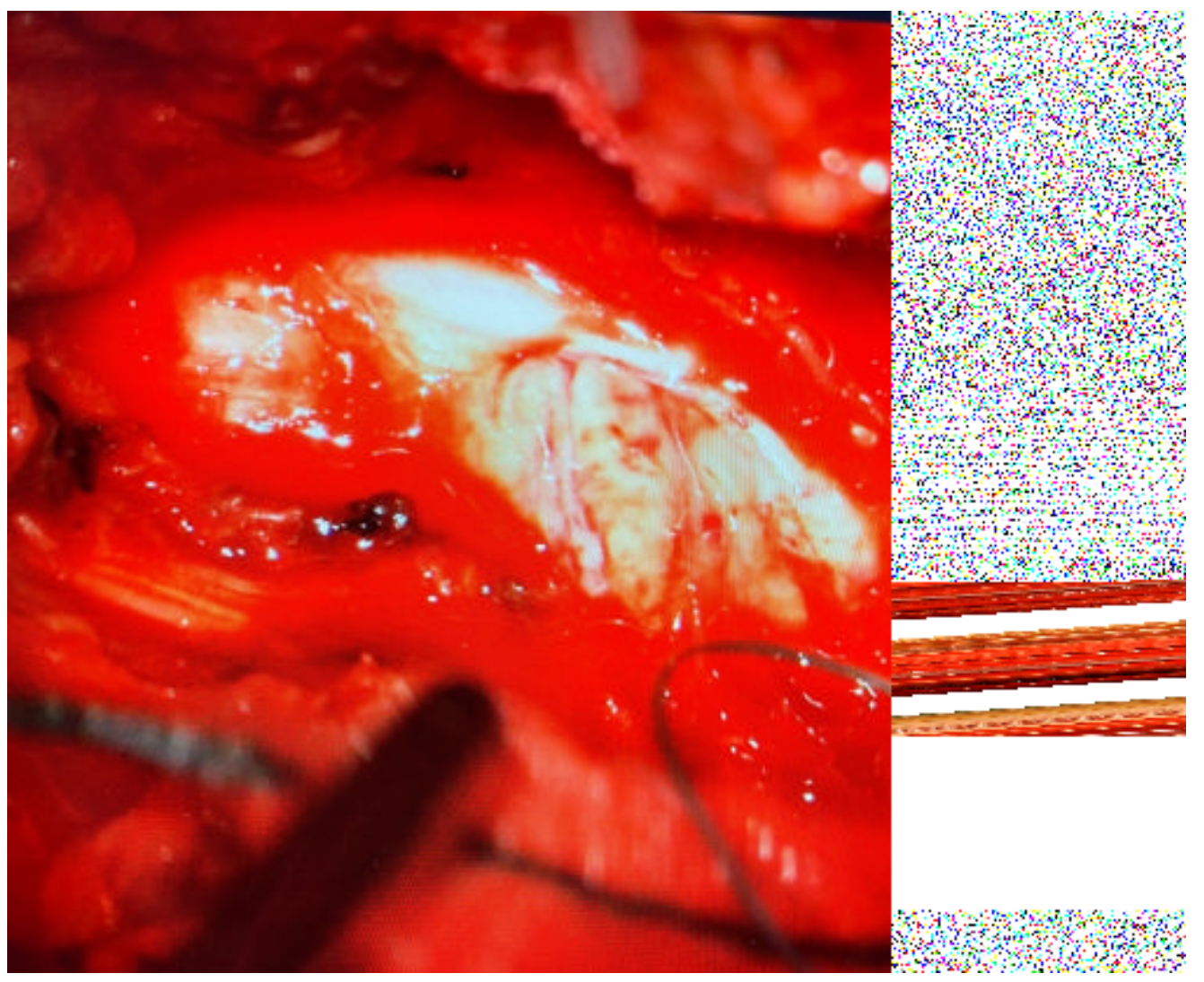

\section{Figure 5}

The appearance of the thoracic cord with hemi section on the right side with contused dura.

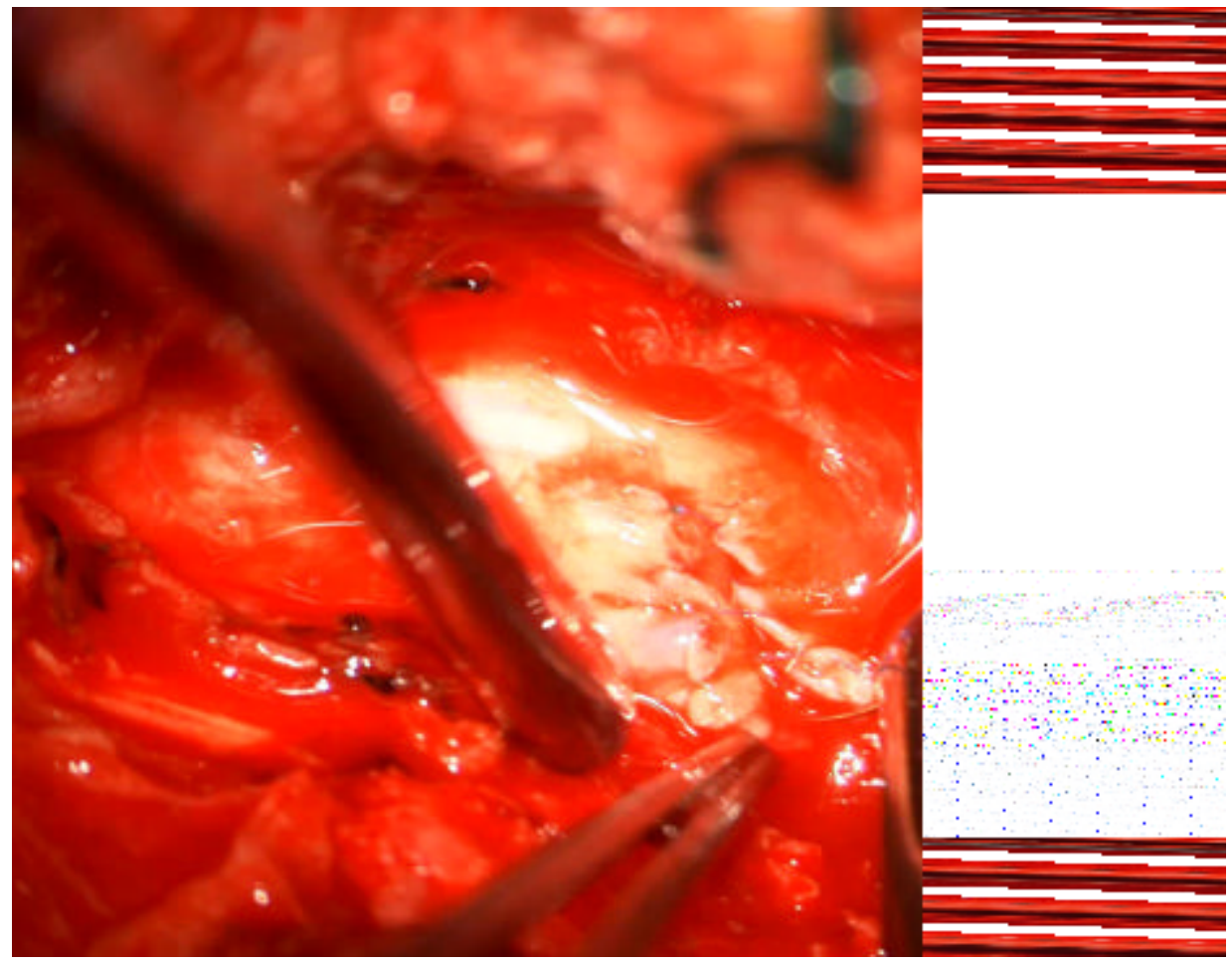

\section{Figure 6}

Repair of the cord from medial to lateral with 7'0 prolene. 


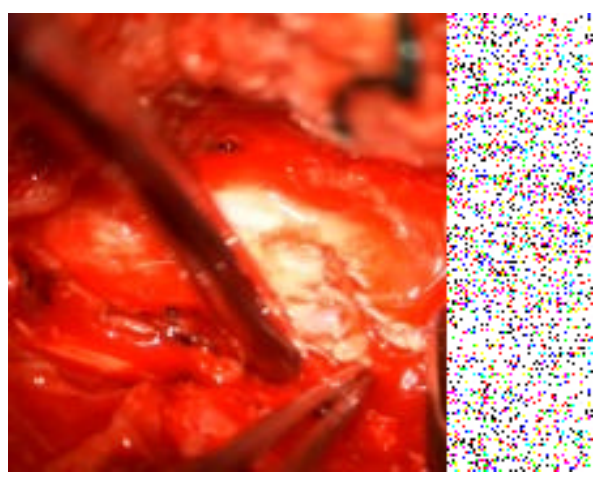

Figure 7

Completion of the repair

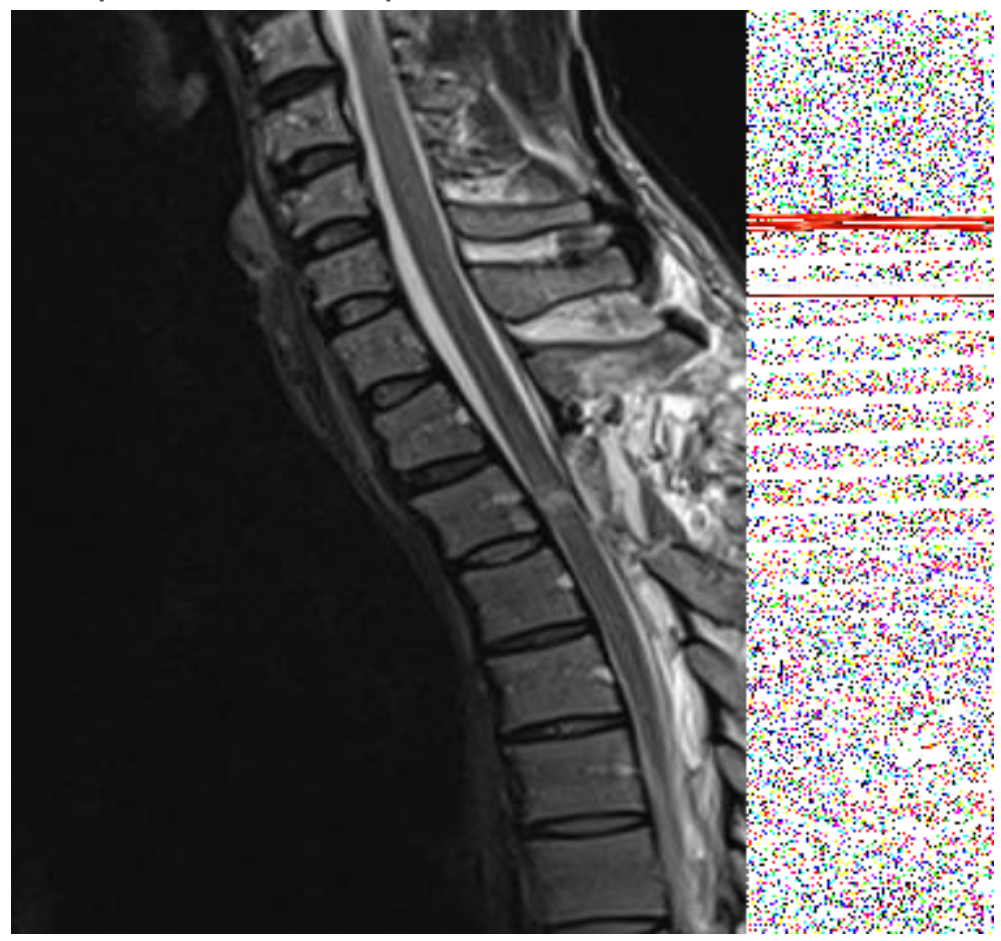

Figure 8

Immediate Post-operative MRI T2 weighted lateral view demonstrating the high signal in the repaired cord and soft tissue changes. 


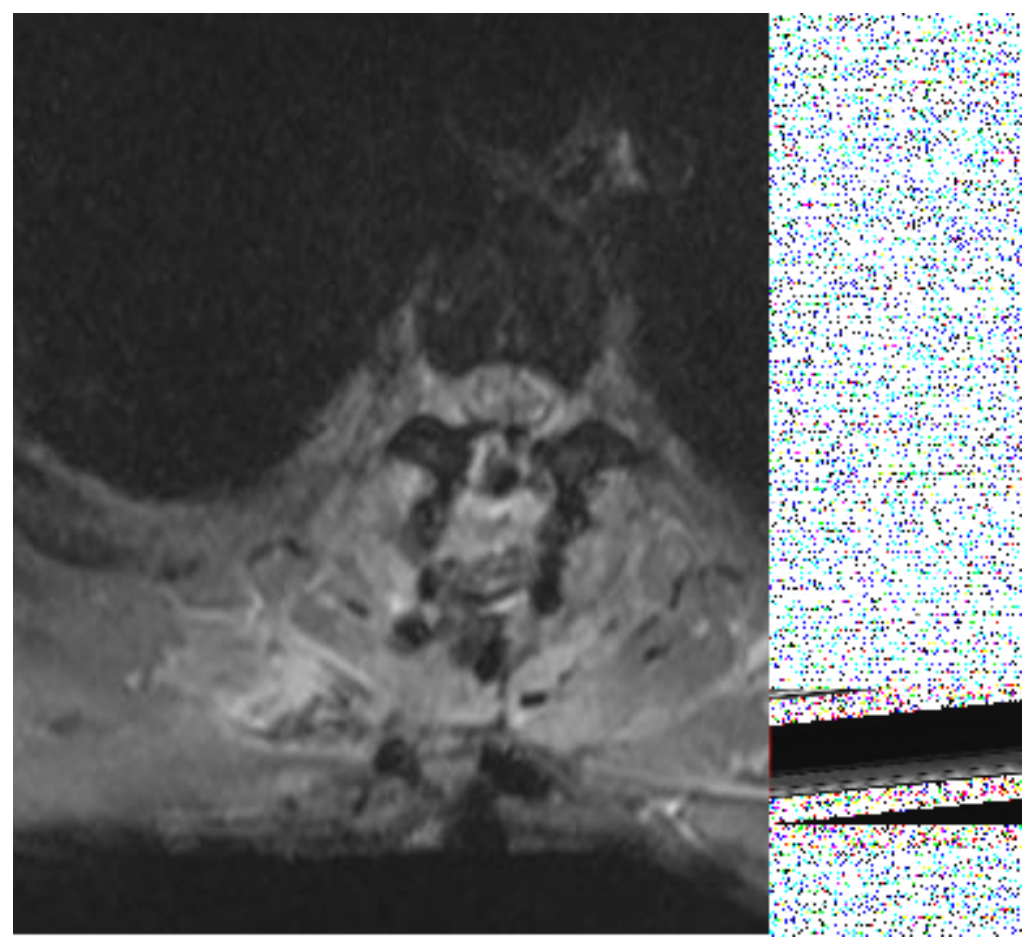

\section{Figure 9}

Immediate Post-Operative MRI Axial T2 weighted MRI at T2/3 level demonstrating the cord high signal in the repaired area.

2

\section{Figure 10}

3 month Post-operative MRI T2 weighted lateral view demonstrating the high signal in the repaired cord and soft tissue changes.

\section{Figure 11}

3 month Post-Operative MRI Axial T2 weighted MRI at T2/3 level demonstrating the cord high signal in the repaired area with evidence of healing. 